\title{
Changes in Fusarium Link Species Composition From Lithuanian Wheat Grain in Years 2005-2007 to 2011-2013
}

\author{
Simonas Sakalauskas, Karina Stumbriene*, Skaidre Suproniene, Povilas Svegzda \\ Laboratory of Microbiology Open Access Joint Research Centre for Agriculture and Forestry, \\ Studentu 15A, Akademija, Kaunas distr., Lithuania
}

\begin{abstract}
Changes in Fusarium species composition from naturally contaminated spring and winter wheat grain from the years 2005-2007 to 2011-2013 are presented. In general, Fusarium infection spring wheat grain was much more frequent than in winter wheat. In 2005-2007 F. avenaceum was dominant in both crops, with $F$. sporotrichioides, F. poae and F. culmorum isolated at lower levels, and F. graminearum, F. tricinctum, F. equiseti and $F$. oxysporum were occasionally found on both spring ant winter wheat. In 2011-2013, F. avenaceum lost its dominating status among Fusarium isolates in both crops, but the species composition of most frequently isolated fusaria in spring and winter wheat was quite different: F. graminearum, F. sporotrichioides, F. culmorum and $F$. avenaceum constituted the major part of fusaria isolated from spring wheat grain, while in winter wheat $F$. poae, F. sportotrichooides and the declining $F$. avenaceum were dominant.
\end{abstract}

Key words: Fusarium, spring wheat, winter wheat, grain infection.

\section{Introduction}

Fungi of genus Fusarium are the major plant pathogens of wheat and other small grain cereals, causing Fusarium head blight (FHB), root rot and seedling blight. Different Fusarium species vary in their contribution to yield loss and, especially, to grain contamination with mycotoxins, as particular species are able to produce mycotoxins of variable plant and animal toxicity levels.

Fusarium avenaceum and to lesser extent $F$. poae, F. culmorum and F. sporotrichioides were regarded as dominant species in Northern Europe (Uhlig, Jestoi \& Parikka, 2007; Yli-Mattila, 2010). Other species, such as $F$. equiseti, $F$. oxysporum and $F$. tricinctum do not constitute a significant part of Fusarium isolated from wheat (Kačergius, Drik, Mankevičienė \& Suproniene, 2008; Mačkinaitė \& Kačergius, 2005; Mačkinaitė, Kačergius, Lugauskas \& Repečkienè, 2006; Mankevičienè, Supronienè, Dabkevičius \& Mačkinaitè, 2007 ; Supronienè et al., 2012). In recent years the situation is changing with $F$. graminearum, one of the most harmful species in regard to mycotoxin production, establishing in the region (Yli-Mattila, 2010).

Fusarium species vary in their distribution, way of spreading, host specificity, pathogenicity level, toxicity to humans and animals, and other biological and ecological characteristics. Therefore, dominant Fusarium species in wheat are subject to crop type (spring or winter), crop kind, weather conditions and fungicide usage.

Of the species most often isolated from Lithuanian wheat, F. avenaceum, F. culmorum,
F. poae, F. sporotrichioides and $F$. tricinctum are commonly found in temperate regions of the world. $F$. graminearum, $F$. equiseti and $F$. oxysporum are considered to be cosmopolitan with no obvious geographical inclinations (Leslie \& Summerel, 2006). F. avenaceum, F. equiseti and F. tricinctum are primarily regarded as soil saprophytes or weak pathogens and secondary invaders (Chelkowski, Manka, Kwasna, Visconti \& Golinski 1989; Leslie \& Summerel, 2006), though $F$. avenaceum is known to cause FHB - one of the most destructive wheat diseases (Kang, Zingen-Sell \& Bucjenauer, 2005). Of the rest, only F. sporotrichioidesis not commonly known to cause FHB, and due to its ability to grow at extremely low temperatures is more likely to be associated with saprophytic way of life and is regarded as a weak pathogen (Leslie \& Summerel, 2006). Toxicity is another important trait of Fusarium species: F. tricinctum, F. oxysporum and $F$. avenaceum are not associated with toxicity to humans and animals and lack the tri5 gene, necessary for production of trichothecene mycotoxins (Tan \& Niessen, 2003). Strains of F. poae were reported to produce nivalenol (NIV), but their toxicity generally regarded as low (Grabarkiewicz-Szczesna, Foremska, Kostecki, Golinski \& Chelkowski, 1999; Leslie \& Summerel, 2006). F. culmorum, F. graminearum, $F$. sporotrichioides and $F$. equiseti are all known as ZEA producers, but there is a significant diversity of synthetized trichothecenes among these species: $F$. culmorum produces DON, F. graminearum DON and NIV, F. sporotrichioides - T-2 toxin, and F. equiseti - T-2 and NIV (Marasas et al., 1984;

\footnotetext{
* Corresponding Author's email:

Karina_stumbriene@yahoo.com
} 
Kokkonen et al., 2010). Production of mycotoxins results in these species being connected with animal toxicoses, moreover, F. oxysporum and F. equiseti are known as human pathogens (Goldschmied, Friedman \& Block, 1993).

Considering the variable physiological characteristics, the study of changes in Fusarium species composition and its connections to environmental conditions and agricultural practices might offer new insights for minimising damage to wheat caused by Fusarium.

\section{Materials and Methods}

Wheat grain samples: winter and spring wheat grain samples for analyses were collected during harvesting in the years 2005-2007 and 2011-2013 from field trials in Institute of Agriculture and commercial fields in Lithuania. A total of 277 samples was collected. (Table 1).

Grain samples were analysed in Plant Pathology and Protection Department and Laboratory of Microbiology of Lithuanian Research Centre for Agriculture and Forestry.

For the laboratory analyses, grain samples of $1 \mathrm{~kg}$ were taken and kept in a freezer at $-20^{\circ} \mathrm{C}$ until the conduction of experiments. The agar plate method was used for internal grain infection estimation. Grain was de-frosted up to room temperature and surfacesterilized for 3 minutes in $1 \% \mathrm{NaOCl}$ before plating into Petri-dishes containing potato dextrose agar (PDA: $250 \mathrm{~g}$ potatoes, $10 \mathrm{~g}$ glucose, $14 \mathrm{~g}$ agar, $1 \mathrm{~L}$ of distilled water) and incubated for $7-8$ days at $25 \pm 2^{\circ} \mathrm{C}$ in dark (Mathur \& Kongsdal, 2003). Fungal grain infection incidence was expressed in percentage. The overgrown Fusarium colonies were isolated, purified and identified according to Nelson, Toussoun, \& Marasas (1983) and Leslie \& Summerell (2006).

Data analysis was done by comparing average values of two 3-year periods: 2005-2007 and 20112013.

\section{Results}

Dominant Fusarium species tend to vary between spring and winter wheat, and 2005-2007 and 20112013 year periods. $35.33 \%$ of spring wheat grain was infected with Fusarium in 2005-2007 (Fig. 1). F. avenaceum being clearly dominant species among these isolates, infecting $17.63 \%$ of grain (Fig. 2). Other frequently isolated Fusarium was 3 to 4 times less abundant: F. culmorum was isolated from $5.73 \%$ of grain, $F$. sporotrichioides $-4.47 \%$, and F. poae $-4.37 \%$. F. tricinctum and F. equiseti were

\section{No. of wheat samples collected for analysis each year}

Table1

\begin{tabular}{ccc}
\hline Year & No. of spring wheat samples & No. of winter wheat samples \\
\hline $2005-2007$ & 44 & 102 \\
\hline $2011-2013$ & 79 & 52 \\
\hline
\end{tabular}

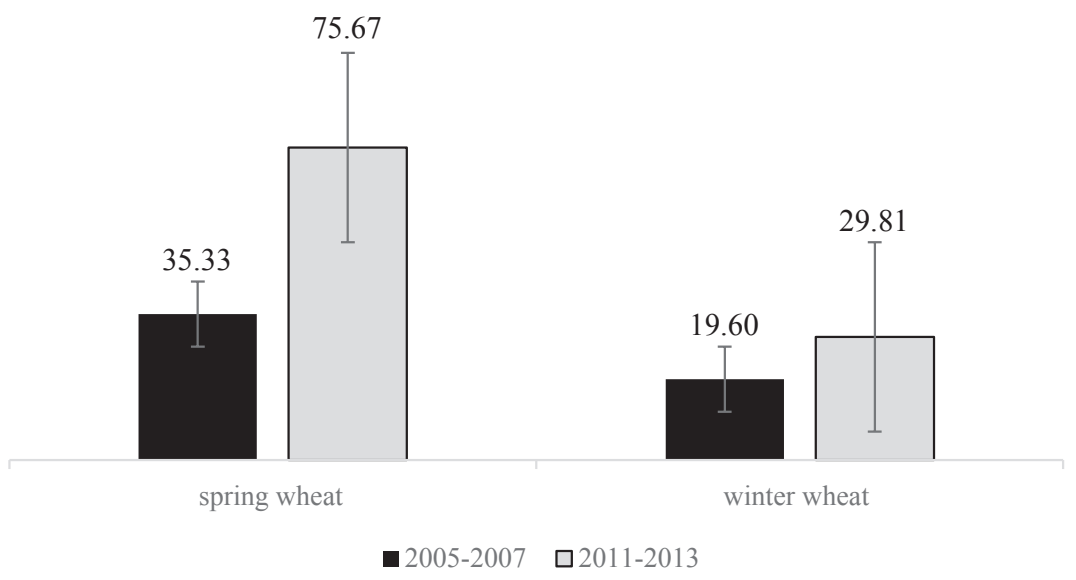

Fig.1. Total count of Fusarium infected grain, \%. 


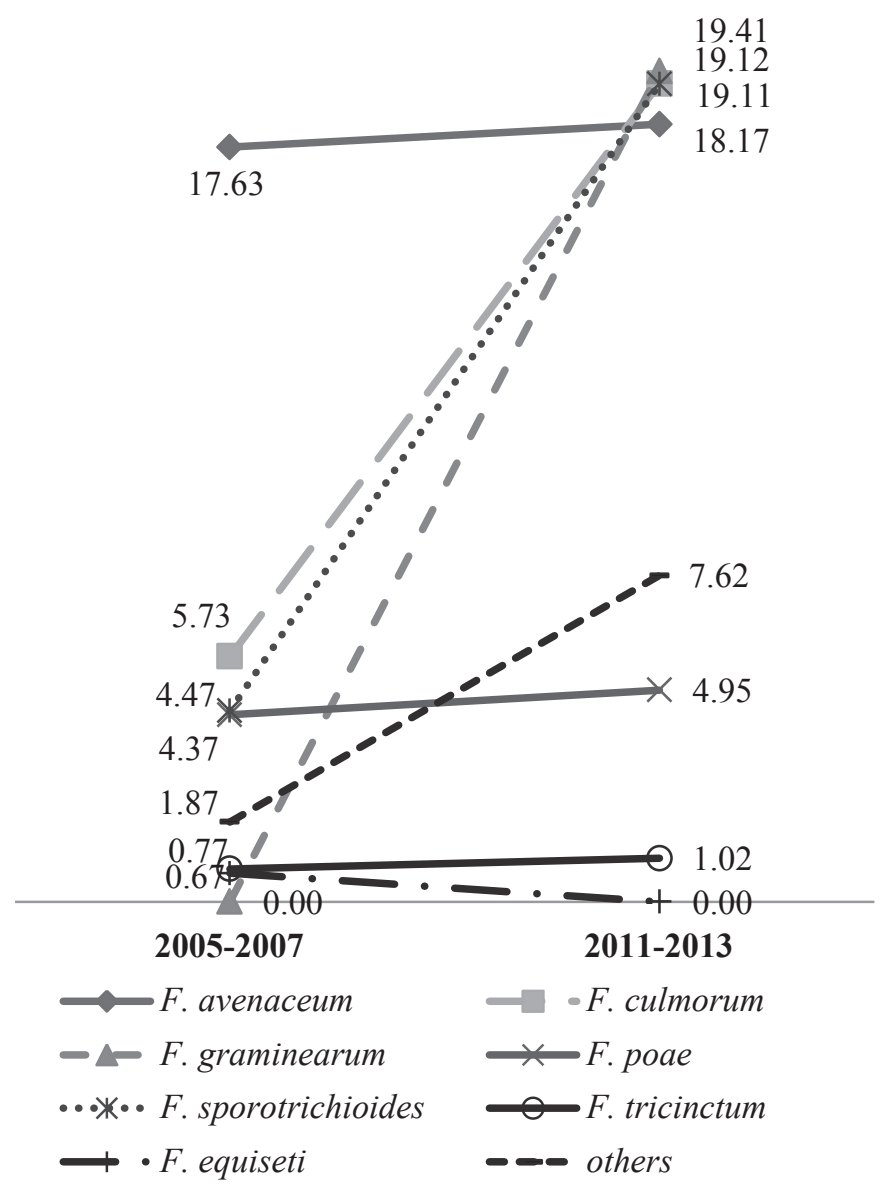

Fig. 2. Changes in Fusarium species composition in spring wheat from the years $2005-2007$ to $2001-2013, \%$.

even less common with $0.77 \%$ and $0.67 \%$ infected grain, respectively. Only solitary F. oxysporum and $F$. graminearum isolates were detected in several samples, with overall count of these species being negligible.

In 2011-2013 total part of Fusarium infected spring wheat grain increased to $75.67 \%$ (Fig. 1). This was mostly conditioned by an increase of $F$. graminearum (up to $19.41 \%$ infected grain), F. sporotrichioides (19.12\%) and F. culmorum (19.11\%), also the part of unidentified "other" fusaria rose to $7.62 \%$ (Fig. 2). Incidence of $F$. avenaceum, $F$. poae and $F$. tricinctum did not change significantly (to $18.17 \%, 4.95 \%$ and $1.02 \%$, respectively), while only very few isolates $F$. oxysporum and $F$. equiseti were detected.

An average of $19.3 \%$ of winter wheat grain was infected with Fusarium in the years 2005-2007 (Fig. 1). F. avenaceum was also clearly dominant species with the incidence of $12.9 \%$ grain (Fig. 3). Other species were considerably less frequent: $F$. poae was found on $1.77 \%, F$. sporotrichioides - 1.57,
F. culmorum -0.57 , and F. tricinctum on $0.33 \%$ of grain. F. graminearum, $F$. equiseti and $F$. oxysporum had very low occurrence. Other species were isolated from $1.97 \%$ of grain.

In the years 2011-2013 Fusarium fungi were isolated from $29.81 \%$ of grain (Fig. 1), the rise in infection incidence in most part associated with the rise of $F$. poae (isolated from $10.17 \%$ of grain) and F. sporotrichioides (8.14\%) (Fig. 3). Incidecne of $F$. avenaceum dropped almost twice to $6.77 \%$. Changes in other Fusarium species occurrence were not that drastic: F. graminearum increased to $2.2 \%$, F. culmorum $-2.16 \%$, F tricinctum $-1.87 \%$, and $F$. equiseti to $0.04 \%$ of grain. Incidence of other fusaria on winter wheat grain remained similar as in 20052007.

\section{Discussion}

An increase in total Fusarium incidence from 2005-2007 to 2011-2013 was obvious in both spring and winter wheat, but in spring wheat this rise was 


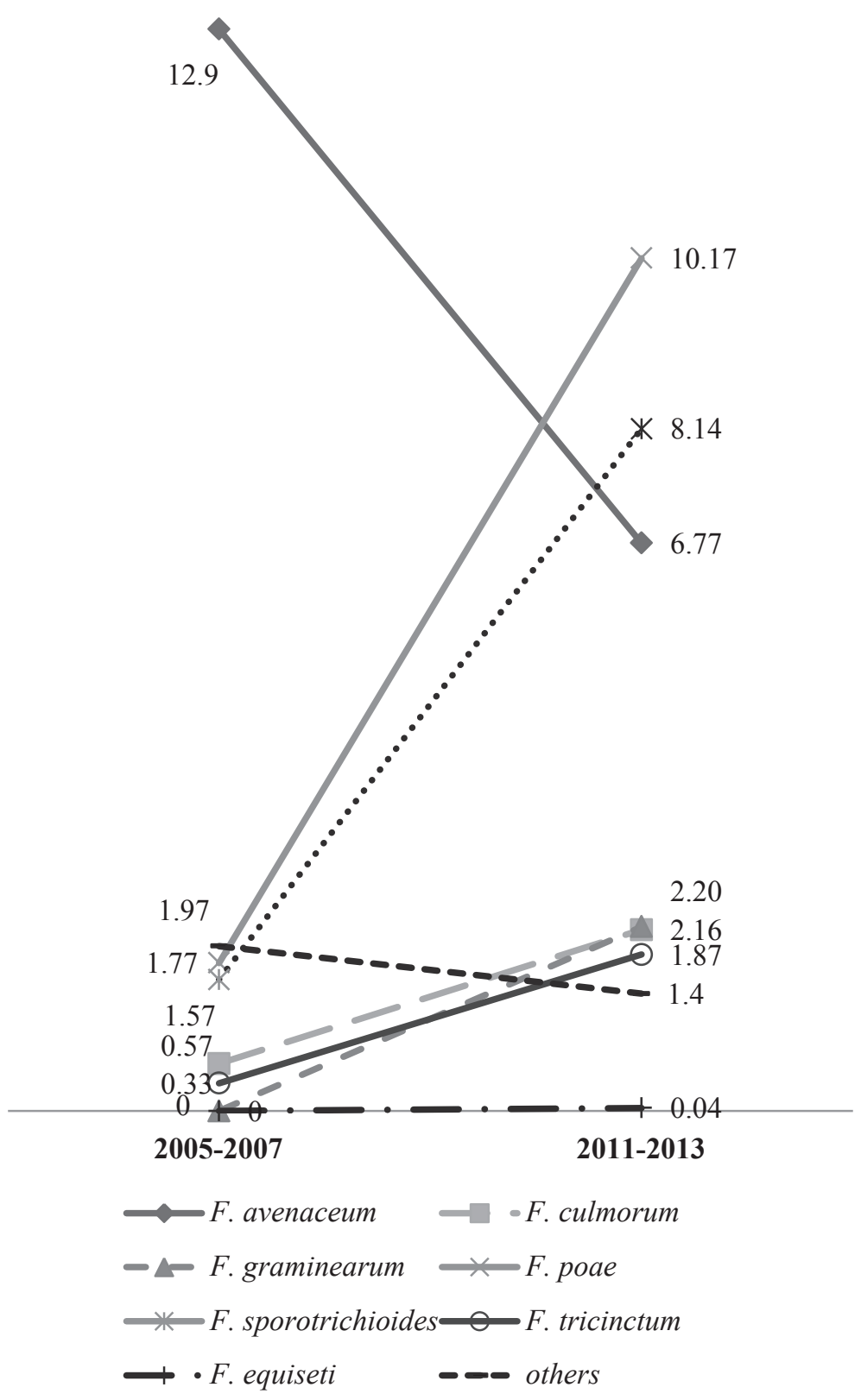

Fig. 3.Changes in Fusarium species composition in winter wheat from years $2005-2007$ to $2001-2013, \%$.

especially steep with total count of Fusarium infected grain doubling. Generally, Fusarium infection level remained much higher in spring than in winter wheat in both time periods: 2005-2007 and 2011-2013.

There was only one dominant Fusarium species in both spring and winter wheat in the years 2005-2007, that is $F$. avenaceum. In this regard, the situation was similar to other parts of Northern Europe (Lõiveke, 2006; Treikale, Priekule, Javoisha, \& Lazareva, 2010; Uhlig, Jestoi \& Parikka, 2007). Other Fusarium species had much lower incidence on wheat grain, and the presently dreaded spring wheat pathogen $F$. graminearum was rarely isolated.

The situation changed substantially in the years 2011-2013. In spring wheat grain there were now 4 dominant species of $F$. graminearum, $F$. sporotrichioides, F. culmorum and $F$. avenaceum. From agricultural point of view this change in species composition is very adverse, since incidence of fungi associated with toxicoses ( $F$. graminearum, F. sporotrichioidesand F. culmorum) and FHB (F. graminearum and $F$. culmorum) rather than those 
of weak toxicity and pathogenicity ( $F$. poae and $F$. avenaceum) has increased notably, considering the reports of Fusarium commonly isolated from wheat in Northern Europe (Yli-Mattila, 2010; Treikale, Priekule, Javoisha, \& Lazareva, 2010).

$F$. poae, F. sporotrichioides and $F$. avenaceum could be regarded as dominant species in winter wheat in the years 2011-2013, although last one is in decline. Considering also that increase in overall incidence of Fusarium is slower than in spring wheat, the situation with winter crops seems somewhat better: there is only one reportedly toxigenic species of $F$. sporotrichioides among 3 dominant, and the incidence of only species commonly associated with FHB, $F$. avenaceum, is falling. The rise in incidence of toxigenic Fusarium in winter wheat was relatively slow, and the part of grain infected with unknown Fusarium species is not increasing - it could mean that no new kind of Fusarium infection is spreading in these crops.

\section{Conclusions}

1. The pattern of Fusarium species composition between periods of years 2005-2007 and 20112013 changed substantially in both spring and winter wheat with one dominant species of $F$. avenaceum being replaced by several dominant species.

2. An obvious increase of $F$. sporotrichioides was recorded in both spring and winter wheat between 2005-2007 and 2011-2013, while incidence dynamics of other species was dissimilar between spring and winter wheat.

3. Incidence increase of both total Fusarium and particular species was notably lower in winter wheat than in spring wheat.

4. Incidence increase in total Fusarium counts in spring wheat was in major part contributed by phytopathogenic and toxigenic species: $F$. graminearum, F. sporotrichioides, F. culmorum, while in winter wheat - by relatively weak pathogens and toxin producers: F. avenaceum.

\section{References}

1. Chelkowski, J., Manka, M., Kwasna, H., Visconti, A. \&, Golinski, P. (1989). Fusarium sporotrichioides (Corda) Sacc. and Fusarium poae Wollenw.: cultural characteristics, toxigenicity and pathogenicity towards cereals. Journal of Phytopathology, 124: 155-161.DOI: 10.1111/j.1439-0434.1989.tb04910.x.

2. Goldschmied, R. A., Friedman, J. \& Block, C. S. (1993). Fusarium spp. isolated from non-ocular sites: a 10 year experience at an Israeli general hospital. Journal de Mycologie Medicale 3: 99102.

3. Grabarkiewicz-Szczesna, J., Foremska, E., Kostecki, M., Golinski, P. \& Chelkowski, J. (1999). Trichothecene accumulation in kernels of corn inoculated with Fusarium poae (Peck) Wollenw. Nahrung, 43: 330-332. DOI:10.1002/ (SICI)1521-3803(19991001)43:5<330::AIDFOOD330>3.0.CO, 2-4.

4. Kačergius, A., Drik, I., Mankevičiene, A., Suproniene, S. (2008). Distribution of fusaria in Lithuanian food grains in 2005-2007. // In Fourth Hungarian Conference of Mycology. Debrecen, Hungary. - ISSN 1217-8950, 2008, vol. 55 (No. 2), 204-205.

5. Kang, Z., Zingen-Sell, I. \&, Bucjenauer, H. (2005). Infection of wheat spikes by Fusarium avenaceum and alterations of cell wall components in the infected tissue. European Journal of Plant Pathology, 111: 19-28. DOI: 10.1007/s10658-004-1983-9.

6. Kokkonen, M., Ojala, L., Parikka, P. \&, Jestoi, M. (2010). Mycotoxin production of selected Fusarium species at different culture conditions. International Journal of Food Microbiology, 143: 17-25. DOI: 10.1016/j. ijfoodmicro.2010.07.015.

7. Leslie, J.F. \& Summerell, B.A. (2006). The Fusarium Laboratory Manual. - Blackwell Publishing, Iowa, USA Oxford, UK: Blackwell Publishing, 2006, 388.

8. Lõiveke, H. (2006). Incidence of Fusarium spp. on several field crops in Estonia and their toxicity towards Bacillus stearothermophilus. Agronomy Research, 4: 273-280.

9. Mačkinaitè, R. \&, Kačergius, A. (2005). Distribution of micromycetes, the potential mycotoxin producers, in stored wheat grains. Botanica Lithuanica, 11 (2): 111-118.

10. Mačkinaitè, R., Kačergius, A., Lugauskas, A. \&, Repečkienè, J. (2006). Contamination of cereal grain by Fusarium micromycetes and their mycotoxins under Lithuanian climatic conditions. Ekologija, 52 (3): 71-79. DOI: http://dx.doi.org/10.6001/ekologija.vi3.1093.

11. Mankevičienè, A., Supronienè, S., Dabkevičius, Z. \&, Mačkinaite, R. (2007). The occurrence of fungi and mycotoxyn content in winter wheat grain in relation to harvesting time. ZemdirbysteAgriculture, 94 (3): 162-175.

12. Marasas, W. F. O., Nelson, P. E. \& Toussoun, T. A. (1984). Toxigenic Fusarium species: Identity and mycotoxicology. University Park, Pennsylvania, USA: The Pennsylvania State University Press, University Park, Pennsylvania. 
13. Mathur, S. B. \& Kongsdal, O. (2003). Common laboratory seed health testing methods for detecting fungi. ISTA, Copenhagen, Denmark: ISTA, 425.

14. Nelson, P. E., Toussoun, T. A. \& Marasas, W. F. O. (1983). Fusarium species: An Illustrated Manual for Identification. University Park, Pennsylvania, USA: The Pennsylvania State University Press, University Park.193.

15. Supronienè, S., Mankevičienė, A., Kadžienè, G., Kačergius, A., Feiza, V., Feizienè, D., Semaškienè, R., Dabkevičius, Z., Tamošiūnas, K. (2012). The impact of tillage and fertilization on Fusarium infection and mycotoxin production in wheat grains. Žemdirbystè (Agriculture), 99 (3): 265-272.

16. Tan, M.-K. \& Niessen, L. M. (2003). Analysis of DNA ITS sequences to determine genetic relationship among, and provide basis for simplified diagnosis of Fusarium species causing crown rot and head blight of cereals. Mycological Research, 107: 811-821.

17. Treikale, O., Priekule, I., Javoisha, B. \& Lazareva, L. (2010) Fusarium head blight: distribution in wheat in Latvia. Communications in Agricultural and Applied Biological Sciences, 75 (4): 627-634.

18. Uhlig, S., Jestoi, M. \& Parikka, P. (2007). Fusarium avenaceum - the North European situation. International Journal of Food Microbiology, 119: 17-24. DOI: 10.1016/j. ijfoodmicro.2007.07.021.

19. Yli-Matilla, T. (2010). Ecology and evolution of toxigenic Fusarium species in cereals in Northern Europe and Asia. Journal of Plant Pathology, 92 (1): 7-18. DOI: 10.4454/jpp. v92i1.10. 